\title{
Biologia floral de Costus spiralis (Jacq.) Roscoe (Costaceae) e mecanismos para evitar a autopolinização
}

\author{
FRANCIELLE PAULINA DE ARAÚJO ${ }^{1,2}$ e PAULO EUGÊNIO OLIVEIRA ${ }^{1}$
}

(recebido: 10 de novembro de 2005; aceito: 7 de dezembro de 2006)

\begin{abstract}
Floral biology of Costus spiralis (Jacq.) Roscoe (Costaceae) and mechanisms to avoid self-pollination). The floral biology of Costus spiralis (Jacq.) Roscoe (Costaceae) was studied on swampy edges of a gallery forest in Uberlândia, Minas Gerais. Costus spiralis is an herb with $0.5 \mathrm{~m}$ to $2.0 \mathrm{~m}$ in height which blossoms from January to April (rainy season). It presents spirally twisted branches with terminal inflorescences that produce only one flower per day. The flowers are subtended by conspicuous red bracts that can attract pollinators. The flowers are hermaphroditic, red, tubular, odourless and present diurnal anthesis. Concentration of sugars in nectar was $c .20 \%$ and volume $c .9 .0 \mu \mathrm{L}$. C. spiralis is a self-compatible, non apomictic species, which does not present spontaneous self-pollination. It presents movement herkogamy to avoid selfpollination. The pollinators of $C$. spiralis were the hummingbirds Phaethornis pretrei (Lesson \& DeLattre) (Phaethornithinae), Eupetomena macroura (Gmelin) and Heliomaster squamosus (Temminck) (Trochilinae). Amazilia fimbriata (Gmelin) acted as nectar robber. Costus spiralis has a floral morphology adapted to pollination by Phaethornithinae, with a long and curved floral tube which conforms with the beak morphology of these birds. The strategy of trapline foraging by Phaethornithinae hummingbirds, favors the reproduction of the plant, increasing pollen flow between groups of $C$. spiralis. There was no difference between germination rates of seeds from self-pollination and cross-pollination, but the seeds produced from natural fruit-set presented significantly higher germination rates than those from hand pollination treatments. The results confirm the efficiency and importance of the hummingbirds as pollen vectors for C. spiralis.
\end{abstract}

Key words - breeding system, Costus spiralis, germination, hummingbirds

RESUMO - (Biologia floral de Costus spiralis (Jacq.) Roscoe (Costaceae) e mecanismos para evitar a autopolinização). A biologia floral de Costus spiralis (Jacq.) Roscoe (Costaceae) foi estudada na borda de uma mata de galeria inundável na Reserva Ecológica do Clube de Caça e Pesca Itororó de Uberlândia, Minas Gerais. Costus spiralis floresce de janeiro à abril (estação chuvosa), é uma erva que pode alcançar de $0,5 \mathrm{~m}$ a 2,0 $\mathrm{m}$ de altura. Apresenta ramos espirais com inflorescências terminais que produzem apenas uma flor por dia. Possui brácteas vermelhas que ajudam na atração de polinizadores. As flores são hermafroditas, vermelhas, tubulosas, apresentam antese diurna e ausência de odor. O néctar apresentou volume de cerca de 9,0 $\mu \mathrm{L}$ e concentração de açúcares por volta de 20\%. Costus spiralis é autocompatível, não apresenta autopolinização espontânea e nem apomixia. Esta espécie apresenta hercogamia de movimento para evitar a autopolinização. Os polinizadores foram os beija-flores Phaethornis pretrei (Lesson \& DeLattre) (Phaethornithinae), Eupetomena macroura (Gmelin) e Heliomaster squamosus (Temminck) (Trochilinae). Amazilia fimbriata (Gmelin) pode agir como pilhador de néctar. Costus spiralis é adaptada à polinização por Phaethornithinae, por apresentar tubo floral grande e curvado que se adapta à morfologia do bico destas aves. A estratégia de alimentação destes beija-flores, utilizando rotas de forrageamento, favorece a reprodução da planta aumentando o fluxo polínico entre os agrupamentos de $C$. spiralis. Não houve diferença nas taxas de germinação de sementes provenientes de autopolinizações manuais e polinizações cruzadas, mas as sementes advindas de polinização natural apresentaram taxas de germinação maiores que aquelas de polinizações manuais. Isto evidencia a eficiência e importância dos beija-flores como vetores de pólen para $C$. spiralis.

Palavras-chave - beija-flores, Costus spiralis, germinação, sistema de polinização

\section{Introdução}

A família Costaceae pertence à ordem Zingiberales, que consiste de oito famílias de monocotiledôneas: Zingiberaceae, Costaceae, Marantaceae, Cannaceae, Lowiacae, Musaceae, Heliconiaceae e Strelitziaceae

\footnotetext{
1. Universidade Federal de Uberlândia, Instituto de Biologia, Caixa Postal 593, 38400-902 Uberlândia, MG, Brasil.

2. Autor para correspondência: franciaralp@yahoo.com.br
}

(Nakai 1941, Cronquist 1981, Dahlgren et al. 1985, Kress 1990, APG II 2003). É constituída por quatro gêneros: Costus, Monocostus, Dimerocostus e Tapeinocheilas os quais são encontrados em áreas tropicais e subtropicais através do Novo e do Velho Mundo, em florestas pluviais e outros ambientes úmidos. Costus é o maior gênero com 125-175 espécies de distribuição pantropical, mas a maioria de suas espécies ocorre nos Neotrópicos (Maas 1972, Stevenson \& Stevenson 2004). 
Geralmente, espécies do gênero Costus crescem em densidades extremamente baixas. A maioria tem ramos espirais com inflorescências terminais que produzem apenas uma flor por dia (raramente duas) além de um período de floração estendido (Schemske 1980, 1981, 1982, Kay \& Schemske 2003). Existem poucos estudos publicados a respeito da biologia reprodutiva de Costaceae, sendo que no Brasil existem dados sobre a fenologia, biologia floral e visitantes de espécies de Costus no âmbito de estudos comunitários na Mata Atlântica (Sazima et al. 1996, Buzato et al. 2000). Dos outros estudos que enfocaram alguns aspectos da biologia reprodutiva desta família, a maioria foi realizado em outros países como Costa Rica, Panamá, Bolívia (Schemske 1981, 1983, Kay \& Schemske 2003) e Venezuela (Ramirez \& Seres 1994, Seres \& Ramirez 1995).

As espécies do gênero Costus já estudadas são polinizadas exclusivamente por abelhas ou beija-flores. A polinização nesse gênero é feita por um número limitado de taxa, indicando alto grau de especialização destas plantas e de seus polinizadores. Algumas espécies podem ser ainda mais especializadas, com polinização especificamente por abelhas Euglossini ou beija-flores eremitas da sub-família Phaethornithinae (Stiles 1981, Sazima et al. 1995, Buzato et al. 2000, Kay \& Schemske 2003).

Costus spiralis (Jacq.) Roscoe ocorre na América do Sul tropical em florestas chuvosas, savanas, ou em afloramentos graníticos (Maas 1972). Esta espécie tem sido usada na medicina popular brasileira no tratamento de afecções urinarias, cálculo renal, no processo de cicatrização, perda do excesso de líquido no corpo, controle da diabete, dentre outras (Albuquerque 1989, Martins et al. 2003, Medeiros et al. 2004). Alguns estudos têm confirmado estas propriedades medicinais (Viel et al. 1999, Antunes et al. 2000, Silva \& Parente 2004), evidenciando a importância do conhecimento de sua biologia reprodutiva para sua conservação e manejo.

O presente estudo apresenta informações sobre a fenologia de floração, a biologia floral, o sistema reprodutivo e os visitantes florais de Costus spiralis, bem como sobre a influência do sistema de cruzamento na produção de frutos e sementes e nas taxas de germinação de sementes desta espécie.

\section{Material e métodos}

O estudo foi realizado na borda de uma ilha de mata de galeria na Reserva Ecológica do Clube de Caça e Pesca Itororó de Uberlândia (CCPIU). A reserva do CCPIU possui 127 ha e está localizada $8 \mathrm{~km}$ a Oeste do perímetro urbano no Município de Uberlândia, MG, nas coordenadas geográficas 18³0'-19³0' S a 4750'-4850' W (Lima et al. 1989).

A região apresenta clima com duas estações bem definidas: uma estação seca e fria, entre os meses de maio a setembro, e uma estação chuvosa e quente de outubro a março, com metade das chuvas concentradas nos meses de novembro a janeiro. De acordo com a classificação de Köppen, o clima pode ser definido como Aw, podendo ocorrer altas temperaturas no verão (acima de $35^{\circ} \mathrm{C}$ ) e geadas ocasionais no inverno (Rosa et al. 1991).

O trabalho de campo foi realizado mais intensivamente no período de janeiro a maio de 2004 e de novembro de 2004 a março de 2005. A fenologia de floração foi acompanhada quinzenalmente, de maneira não quantitativa, de janeiro de 2004 a março de 2005, sendo registrados os períodos da formação das inflorescências, emissão de flores e formação de frutos. O padrão de floração da espécie foi descrito de acordo com a classificação de Newstrom et al. (1994). Foram considerados picos de floração quando a maioria dos indivíduos na área de estudo apresentava flores. Esta espécie é encontrada na reserva do CCPIU no interior e borda das ilhas de mata. Os indivíduos podem ocorrer de forma isolada ou formando pequenos agrupamentos (de dois a quatro indivíduos). Quando isolados podem apresentar de uma a 25 inflorescências formando touceiras. Alguns indivíduos isolados ocorrem também ao longo da vereda, sempre próximos a margem do curso de água, onde o solo é mais úmido.

Para o estudo da biologia floral, foram obtidos no campo, dados das flores como cor, odor, recompensas florais, medidas do tubo da corola, número de flores/inflorescência/indivíduo. Para a caracterização da morfologia floral, foram coletadas 15 flores de quatro indivíduos diferentes, tendo sido conservadas em álcool 70\%. Foram efetuadas medidas do maior diâmetro e do comprimento (da base à abertura) do tubo floral. Dadas as dificuldades logísticas para acesso à área de estudo, para a definição do horário de abertura das flores, algumas inflorescências foram coletadas, mantidas em água no laboratório e observadas de hora em hora até a antese. O estágio de abertura foi comparado depois com flores no campo no início da manhã.

A viabilidade polínica de 18 botões florais em pré-antese oriundos de cinco agrupamentos diferentes foi estimada pela coloração citoplasmática, usando a técnica do carmim-acético (Radford et al. 1974). A receptividade estigmática foi inferida visualmente, quando ocorria a separação dos lobos estigmáticos (Kearns \& Inouye 1993).

A produção de néctar foi medida no período da manhã por volta das $9 \mathrm{~h} 00 \mathrm{em} 12$ flores e no período da tarde por volta das $15 \mathrm{~h} 00$ em sete flores ensacadas previamente no estágio de botão. $\mathrm{O}$ volume de néctar acumulado foi medido usando-se capilares graduados $(10 \mu \mathrm{L})$ e a concentração medida com refratômetro de mão. As medidas refratométricas "g açúcar/g solução" foram convertidas em "g açúcar/L 
néctar" (Kearns \& Inouye 1993). As médias do volume e concentração de açúcares no néctar foram utilizadas para calcular a quantidade de recompensa em calorias por flor. A relação apresentada por Dafni (1992) foi utilizada para transformar "mg de açúcar" em "calorias" sendo $1 \mathrm{mg}$ açúcar $=4$ calorias. A partir destes dados e do número médio de flores amostrados por dia foi estimado o recurso em calorias que a planta pode oferecer em cada agrupamento.

Foram coletados exemplares da espécie para herborização com a técnica usual de Fidalgo \& Bononi (1984), que foram incorporados ao acervo do Herbarium Uberlandense (HUFU) do Instituto de Biologia da Universidade Federal de Uberlândia (HUFU 41696).

O monitoramento do comportamento dos visitantes florais foi feito por meio de observações visuais in situ, e por fotografias. As observações foram feitas em 18 dias diferentes ao longo do estudo, no período entre $7 \mathrm{~h} 00$ e $16 \mathrm{~h} 00$. As sessões tiveram duração variável de uma a quatro horas ininterruptas e totalizaram 45 horas de observação. Foram anotados os visitantes florais, suas freqüências de visitas e o número de flores visitadas. As identificações dos beijaflores foram baseadas em Grantsau (1989).

Para análise do sistema de reprodução, 45 inflorescências de cinco indivíduos diferentes foram isoladas com sacos de organza de "nylon". Após a abertura das flores foram feitos os seguintes testes: 1) autopolinizações manuais (o pólen de uma dada flor foi depositado manualmente no estigma da mesma flor); 2) autopolinizações espontâneas (botões em pré-antese foram ensacados, sem nenhum tratamento posterior); 3) agamospermia (as flores tiveram a antera e o estigma retirados, sendo novamente ensacadas); 4) polinizações cruzadas (o pólen trazido de planta distante pelo menos 30 metros foi depositado no estigma da flor); 5) controle (flores sem nenhum tratamento foram marcadas e acompanhadas para avaliar a eficiência da polinização natural). O sucesso dos tratamentos foi avaliado pela formação de frutos maduros, pelo número de sementes formadas e pelas taxas de germinação de sementes obtidas a partir de cada tratamento.

Para a observação do crescimento dos tubos polínicos, flores submetidas aos testes de autopolinização e polinização cruzada, foram coletadas duas, quatro, seis, oito e dez horas após o tratamento e fixadas em álcool $70 \%$, sendo posteriormente observadas em microscopia de fluorescência de acordo com a técnica de Martin (1959).

Para quantificar o efeito do sistema de cruzamento na germinação, frutos foram coletados no inicio de abril de 2004, aproximadamente dois meses após as polinizações. As sementes de cada tipo de cruzamento foram quantificadas e tiveram o arilo retirado. Estas sementes foram pesadas e armazenadas por um período de 30 dias até serem semeadas. As sementes oriundas de três dos tratamentos (autopolinização, polinização cruzada e polinização natural) foram plantadas em câmaras úmidas contendo solo da zona de fundo de vereda (borda da mata de galeria) e um pouco de areia. Todas as câmaras foram mantidas em casa de vegetação com cobertura de sombrite $50 \%$ e sob condições naturais de luz e temperatura. O trabalho foi desenvolvido em delineamento inteiramente casualizado com os três tratamentos (quatro repetições de 30 sementes cada), totalizando 360 sementes semeadas. A duração do experimento foi de 135 dias contando a partir do dia da semeadura. As contagens foram realizadas diariamente e o critério de germinação adotado foi a protrusão da radícula (Castro \& Hilhorst 2004).

Para análise comparativa da formação de frutos após os vários tratamentos de polinizações controladas foi utilizado o teste de Qui-quadrado utilizando o aplicativo Bioestat 2.0 (Ayres et al. 2000). Todas as demais análises estatísticas foram conduzidas usando o programa Prophet.5.0 (NIH/BBN Software Group - http://www-prophet.bbn.com). Análise de variância seguida de comparação post-hoc pelo teste de Tukey ou Kruskal-Wallis seguido de comparação post-hoc pelo teste de Dunn foram utilizados para as análises de germinação após avaliação da normalidade e homogeneidade dos dados.

\section{Resultados}

$\mathrm{Na}$ área de estudo Costus spiralis formou as primeiras inflorescências a partir de dezembro, começando a liberar as primeiras flores no início de janeiro. O pico de floração ocorreu nos meses de janeiro e fevereiro, sendo que esta fenofase se estendeu até abril, tendo ainda algumas flores em maio. A frutificação ocorreu a partir do final de março e se estendeu até junho.

Costus spiralis é uma erva que pode alcançar de $50 \mathrm{~cm}$ a $2 \mathrm{~m}$ de altura aproximadamente. Apresenta inflorescências racemosas em forma de espiga (figura 1), possui brácteas vermelhas fechadas e sobrepostas, dentro das quais desenvolvem-se os botões florais e frutos. As inflorescências apresentam uma média de 8,6 $\pm 2,3 \mathrm{~cm}(n=8)$ de comprimento. Elas podem conter cerca de $42 \pm 12$ flores $(n=12)$, cada uma inserida numa bráctea. Porém as 5,7 $\pm 1,9(n=6)$ primeiras brácteas mais basais não apresentam flores. A maturação das flores e frutos ocorre em espiral, de baixo para cima.

As flores são vermelhas, sendo o tubo floral formado por três pétalas fundidas na base com o estame petalóide e um lábio formado pela união de cinco estaminódios. O comprimento do tubo é de 50,29 \pm $4,48 \mathrm{~mm}(n=15)$ sendo o maior diâmetro de 10,64 \pm $1,64 \mathrm{~mm}(n=15)$ (figura 2).

O único estame fértil da flor é petalóide, apresenta duas tecas com deiscência longitudinal (figura 3 ) sendo 
envolvido pelo lábio. A altura das anteras desde a base do tubo foi de $44,90 \pm 1,93 \mathrm{~mm}(n=15)$. O ovário é ínfero, tricarpelar, trilocular com placentação axilar e muitos óvulos por lóculo. Possui um estilete com fixação terminal posicionado entre as duas tecas da antera. $\mathrm{O}$ estigma é bilobulado do tipo úmido, com um dos lóbulos pouco mais curto que o outro. $\mathrm{O}$ estigma é suportado pela antera, ficando exposto pouco acima desta e atingindo uma altura de $45,70 \pm 1,84 \mathrm{~mm}(n=15)$ desde a base do tubo (figuras 3-4). O estigma apresenta um apêndice dorsal que parece possuir uma função específica de reposicionar o estigma após as visitas dos polinizadores (figura 5).

As flores não emitem odor, sendo que a recompensa floral é o néctar. $\mathrm{O}$ néctar acumulado no período da manhã (ca. 9h00) foi em média 9,12 $\pm 4,20 \mu \mathrm{L}(n=12)$ e concentração de açúcares de $21,6 \pm 6,3 \%(n=12)$. O néctar acumulado até o período da tarde (15h00) apresentou um volume de $13,8 \pm 4,7 \mu \mathrm{L}(n=7) \mathrm{e}$ concentração de $24,4 \pm 4,7 \%$ ( $n=7)$. A oferta calórica, utilizando os valores obtidos nas medidas da tarde, foi estimada em 15,73 $\pm 8,50$ calorias flor $^{-2}(n=7)$. Dessa forma, em um agrupamento contendo 25 inflorescências no qual cada inflorescência apresenta pelo menos uma flor aberta, o recurso instantâneo pode alcançar um valor de $c a .393$ calorias.

Os visitantes florais de Costus spiralis foram os beija-flores Phaethornis pretrei (Lesson \& DeLattre) (Phaethornithinae) (figura 6), Eupetomena macroura (Gmelin), Heliomaster squamosus (Temminck) e Amazilia fimbriata (Gmelin) (Trochilinae). Num total de 45 horas de observação, Phaethornis pretrei foi o mais freqüente tendo sido registrado 32 vezes, visitando um total de 248 flores e aparentemente apresentando rotas de forrageamento, isto é, visitando de maneira sistemática as flores existentes nos agrupamentos formados por C. spiralis e logo em seguida partindo para outros agrupamentos, chegando e partindo de direções similares em cada surto de visita. Além disso, suas visitas se estenderam ao longo do dia, desde a abertura das flores até o murchamento das mesmas. Eupetomena macroura foi avistado três vezes, visitando um total de 15 flores, permanecendo próximo das manchas de recursos e vocalizando num comportamento aparentemente territorial. Heliomaster squamosus foi registrado na área visitando as flores de Sinningia elatior (Kunth) Chautems (Gesneriaceae) e foi observado em um único dia, duas vezes, em cinco flores de C. spiralis. Amazilia fimbriata foi registrado duas vezes em $C$. spiralis, porém este beija-flor, dado seu bico relativamente curto, parece não ter acesso ao néctar de maneira legítima. Foi observado tentando tomar o néctar pela base do tubo floral, ficando este danificado após a visita desta espécie de beija-flor.

Foi observada também uma visita da abelha Eulaema (Apeulaema) nigrita Lepeletier (figura 7) e uma borboleta Hesperiidae. A abelha encontrou dificuldades para entrar no tubo floral e, provavelmente por isso, não foram feitos outros registros nesta planta. A borboleta Hesperiidae foi observada apenas duas vezes visitando $C$. spiralis.

Costus spiralis é hermafrodita, homogâmica e autocompatível, mas não apresenta autopolinização espontânea e nem apomixia (tabela 1). Os pistilos, fixados após autopolinização e polinização cruzada, não apresentaram diferenças entre si na velocidade do desenvolvimento dos tubos polínicos e estes alcançaram os óvulos cerca de 6 horas após a polinização, independente do tratamento (figura 8). O fruto é uma cápsula loculicida (figura 9) com muitas sementes de coloração preta com arilo branco. O número de sementes formadas de polinizações artificiais foi menor do que o das sementes formadas a partir de polinização natural e o peso das sementes foi diferente entre tratamentos de polinização (tabela 2).

Os botões florais são liberados pela inflorescência lentamente ao longo do dia e apresentam-se completamente expostos a partir das $22 \mathrm{~h} 00$. Os botões começam a se abrir a partir de 00h00, mas a deiscência das anteras e exposição do estigma ocorrem entre $4 \mathrm{~h} 00-5 \mathrm{~h} 00$. Os tubos florais murcham por volta das 15h00-16h00 e todo o conjunto formado pelo tubo floral, estigma e estilete, se desprende. A liberação do pólen se dá em grãos isolados (figura 10), tendo sido registrada a viabilidade média de $89,0 \pm 7,7 \%$ ( $n=18$ flores).

Costus spiralis apresenta adaptação mecânica para impedir que ocorra a autopolinização. $\mathrm{O}$ estigma bilobulado pode apresentar duas configurações: a forma receptiva (lóbulos separados) e a forma não receptiva (lóbulos unidos). Quando a flor é visitada por um beijaflor, o bico deste carregado de pólen proveniente de outras flores é inserido na corola. O lóbulo anterior é um pouco mais comprido e é movimentado junto com o bico deixando a superfície receptiva exposta em contato com este. Assim, os grãos de pólen são aderidos a esta superfície. Quando o bico é retirado da corola, o lóbulo volta junto com este no mesmo sentido, sendo comprimido contra o outro lóbulo e a parede formada pela porção petalóide do estame. Desta forma, os dois lóbulos estigmáticos ficam unidos deixando protegida a superfície receptiva. Os grãos de pólen da própria flor que aderirem ao bico do beija-flor serão transportados 

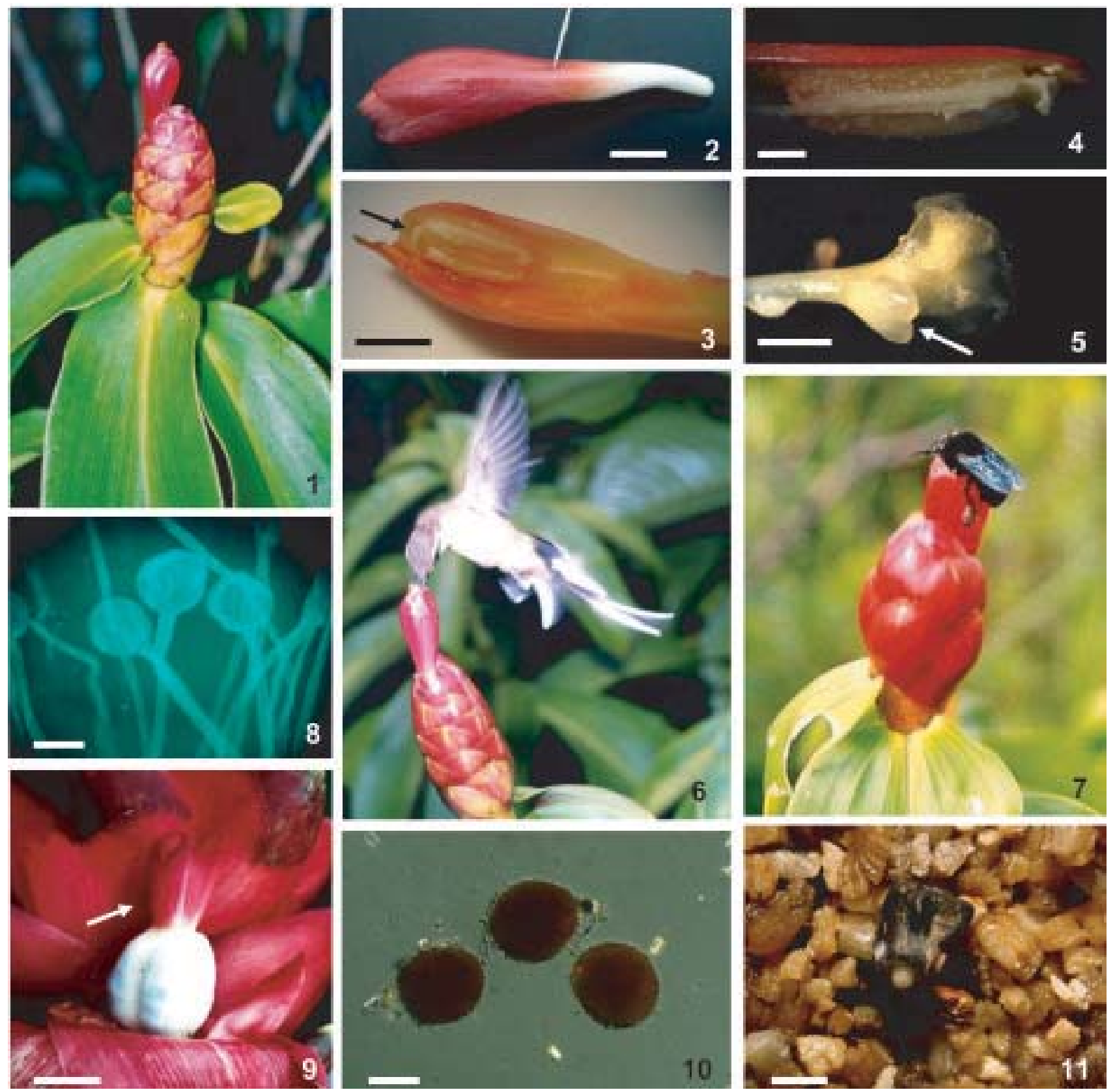

Figuras 1-11. Morfologia floral e reprodução de Costus spiralis. 1. Inflorescência com uma flor exposta. 2. Tubo floral. 3. Tubo floral em corte longitudinal, mostrando estigma (seta) localizado pouco acima da antera. 4. Vista lateral do estigma e da antera. 5. Apêndice dorsal do estigma (seta). 6. Phaethornis pretrei visitando flor de C. spiralis (Foto: C.P. Coelho). 7. Abelha Eulaema (Apeulaema) nigrita visitando flor de C. spiralis (Foto: L.C. Rocha). 8. Grãos de pólen germinado no teste de polinização cruzada após duas horas. 9. Fruto de $C$. spiralis (seta indica cálice persistente). 10. Grãos de pólen viáveis no teste de coloração carmim-acético. 11. Semente de C. spiralis germinando. (Foto: C. Mendes-Rodrigues). Barras = 10 mm (2, 3, 9), $2 \mathrm{~mm}(4,11), 1 \mathrm{~mm}(5), 15 \mu \mathrm{m}(8,10)$.

Figures 1-11. Floral morphology and reproduction of Costus spiralis. 1. Inflorescence. 2. Floral tube. 3. Longitudinal section of the floral tube showing stigma (arrow) above the anther. 4. Lateral view of the stigma and the anther. 5. Stigma dorsal appendix (arrow). 6. Phaethornis pretrei visiting C. spiralis (Photo: C.P. Coelho). 7. Eulaema (Apeulaema) nigrita bee visiting C. spiralis (Photo: L.C. Rocha). 8. Pollen grain germination two hours after cross-pollination. 9. Fruit of C. spiralis (arrow indicates persistent calyx). 10. Viable pollen grains after aceto-carmim staining. 11. Germinating C. spiralis seed (Photo: C. MendesRodrigues). Bars $=10 \mathrm{~mm}(2,3,9), 2 \mathrm{~mm}(4,11), 1 \mathrm{~mm}(5), 15 \mu \mathrm{m}(8,10)$. 
sem entrar em contato com a superfície receptiva do seu próprio estigma. Com a ajuda do apêndice dorsal, o estigma pode voltar à posição original e posteriormente os lóbulos se separam e ficam novamente expostos para receber nova carga polínica (figura 5).

O número de sementes por fruto, o peso e a porcentagem de germinação para as sementes provenientes de polinização natural foram significativamente maiores do que nas sementes provenientes de polinizações manuais. Porém a germinação das sementes (figura 11) dos tratamentos de polinização manual (autopolinização e polinização cruzada) não diferiu significativamente (tabela 2).

\section{Discussão}

Costus spiralis apresenta padrão de floração anual com duração intermediária (4 a 5 meses) (Newstrom et al. 1994). Este padrão é semelhante ao descrito para populações da mesma espécie para áreas da Mata Atlântica (Buzato et al. 2000). Como outras espécies do gênero (Schemske 1983), C. spiralis floresce na estação chuvosa e frutifica no fim desta estação. Apresenta estratégia de floração do tipo disponibilidade regular (Newstrom et al. 1994), com a produção de uma ou duas flores por inflorescência por dia durante um período prolongado como ocorre, por exemplo, em Canistrum aurantiacum E. Morren (Bromeliaceae) (Siqueira Filho \& Machado 2001).

Costus spiralis, assim como outras espécies do gênero possui inflorescências com brácteas vermelhas (Stevenson \& Stevenson 2004) que funcionam como uma unidade de atração para os polinizadores (Stiles 1981, Buzato et al. 2000). As flores de C. spiralis são morfologicamente complexas e similares a outras espécies de Costus polinizadas por aves, que geralmente são alaranjadas, vermelhas ou rosa, com as brácteas da mesma cor, enquanto as flores das espécies polinizadas por abelhas freqüentemente são brancas, amarelas, alaranjadas e raramente vermelhas, com as brácteas das inflorescências geralmente verdes (Sakai et al. 1999). As flores polinizadas por aves geralmente apresentam o lábio pequeno e tubular enquanto naquelas polinizadas por abelhas este lábio é curto e largo podendo ser usado como plataforma de pouso (Sakai et al. 1999, Specht et al. 2001).

Os valores de volume e concentração de açúcares no néctar encontrados em Costus spiralis, são mais próximos aos encontrados em outras plantas ornitófilas, como por exemplo Esterhazia macrodonta (Cham.) Benth. (Scrophulariaceae), com volume de 13,4 $\mu \mathrm{L}$ e concentração de 26\% (Freitas \& Sazima 2001), que quando comparado a outras espécies de Costus não ornifófilas tais como, C. allenii Maas volume de 40,6 $\mu \mathrm{L}$ e concentração de $37 \%$ ou C. laevis Ruiz \& Pav. volume de $42,4 \mu \mathrm{L}$ e concentração de $33 \%$ (Schemske 1981). Assim, o padrão de coloração e estrutura das flores, bem como os valores de volume e concentração de néctar, são compatíveis com aqueles que vêm sendo reportados para outras espécies ornitófilas (Sazima et al. 1995).

As flores de C. spiralis são adaptadas à polinização por beija-flores de bico longo da sub-família Phaethornithinae, pois apresentam tubo da corola levemente curvado e longo. O comportamento de visita de Phaethornis pretrei em linhas de captura, "trapline" (Feinsinger \& Colwell 1978), bem como sua freqüência de visitas parecem garantir maior

Tabela 1. Resultados dos testes de polinizações controladas em Costus spiralis (Costaceae) em borda de mata de galeria na Reserva Ecológica do Clube Caça e Pesca Itororó de Uberlândia, MG. Porcentagens seguidas de letras distintas nas colunas diferem siginficativamente pelo teste de Qui-quadrado com $P<0,05$.

Table 1. Results of hand pollination tests in Costus spiralis (Costaceae), at the Ecological reserve of the Clube Caça e Pesca Itororó de Uberlândia, MG. Percentages followed by distinct letters differed significantly when using chi = aquare test at $P<0.05$.

\begin{tabular}{lccr}
\hline Tratamento & $\begin{array}{c}\text { Flores polinizadas } \\
(n)\end{array}$ & $\begin{array}{c}\text { Frutos formados } \\
(n)\end{array}$ & $\begin{array}{c}\text { Sucesso de frutificação } \\
(\%)\end{array}$ \\
\hline Autopolinização manual & 77 & 56 & $72,72^{\mathrm{a}}$ \\
Autopolinização espontânea & 358 & 1 & $0,27^{\mathrm{b}}$ \\
Teste para agamospermia & 76 & 0 & $0^{\mathrm{b}}$ \\
Polinização cruzada & 70 & 59 & $84,28^{\mathrm{a}}$ \\
Polinização natural & 781 & 654 & $83,73^{\mathrm{a}}$ \\
\hline
\end{tabular}


Tabela 2. Número, peso e germinabilidade das sementes formados a partir de polinização cruzada, autopolinização manual e polinização natural em Costus spiralis (Costaceae). Análise de variância $(F)$ ou Kruskal-Wallis $(H)$ foram utilizados para avaliar diferenças entre os tratamentos.

Table 2. Number, weight and germinability of the seeds from cross pollination, self-pollination and natural pollination of Costus spiralis (Costaceae). ANOVA $(F)$ or Kruskal-Wallis $(H)$ were used to evaluate differences between treatments.

\begin{tabular}{lccc}
\hline Tratamento & $\begin{array}{c}\mathrm{N}^{\mathrm{o}} \text { de sementes } \\
\text { por fruto }\end{array}$ & $\begin{array}{c}\text { Peso das sementes } \\
(\mathrm{g})\end{array}$ & $\begin{array}{c}\text { Germinabilidade } \\
(\%)^{*}\end{array}$ \\
\hline Polinização cruzada & $15,58 \pm 9,5(n=40)^{\mathrm{b}}$ & $0,0070 \pm 0,0013^{\mathrm{c}}$ & $63,33 \pm 4,71^{\mathrm{b}}$ \\
Autopolinização manual & $11,73 \pm 6,4(n=44)^{\mathrm{b}}$ & $0,0078 \pm 0,0013^{\mathrm{b}}$ & $62,50 \pm 6,31^{\mathrm{b}}$ \\
Polinização natural & $22,88 \pm 9,1(n=50)^{\mathrm{a}}$ & $0,0084 \pm 0,0014^{\mathrm{a}}$ & $92,50 \pm 5,69^{\mathrm{a}}$ \\
$F$ ou $H(p)$ & $H=32,179(P=0,001)$ & $H=22,92(P<0,05)$ & $F=37,09(P<0,01)$ \\
\hline
\end{tabular}

Média \pm desvio padrão, seguidas de letras distintas nas colunas diferem significativamente pelos testes post-hoc de Tukey ou de Dunn, $P$ $<0,05$.

Mean \pm standard deviation, followed by distinct letters differed significantly when using Tukey or Dunn tests for post-hoc comparison at $P<0,05$.

variabilidade genética à população de C. spiralis. Além disso, a eficiência das visitas e comportamento de forrageamento pode explicar a maior formação de frutos e sementes por polinização natural quando comparada com polinizações manuais. Em áreas de Mata Atlântica $C$. spiralis também é visitada por espécies de beija-flores da subfamília Phaethornithinae:

Phaethornis eurynome e Ramphodon naevius (Buzato et al. 2000).

Apesar de $C$. spiralis estar adaptada à polinização por Phaethornithinae, recebe também visitas de beijaflores da sub-família Trochilinae. Eupetomena macroura, por exemplo, consegue utilizar o néctar, mas devido a seu comportamento aparentemente territorial, que parece ser típico da espécie (Sick 1997), provavelmente promove muito mais autopolinizações ou polinização entre flores de um mesmo indivíduo, como observado para outras espécies ornitófilas (Siqueira Filho \& Machado 2001).

A oferta de quantidade relativamente alta de néctar por flor, porém baixa por indivíduo ou agrupamento, apresentada por $C$. spiralis, pode ser outra adaptação da planta ligada à subfamília Phaethornithinae, pois estes beija-flores utilizam rotas de forrageamento e podem ajustar seu tempo de retorno às flores conforme o néctar vai sendo reposto (Gill 1988). As outras espécies de beija-flores registradas em $C$. spiralis pouco interferem na reprodução desta planta, pois raramente às visitam e, no caso de $A$. fimbriata, não estão bem adaptadas à morfologia da planta. A borboleta Hesperiidae e a abelha Eulaema (Apeulaema) nigrita registradas provavelmente contribuem muito pouco para a polinização de $C$. spiralis, sendo suas visitas muito raras e morfologicamente pouco adaptadas à polinização deste tipo de flor.

O sistema reprodutivo de $C$. spiralis é semelhante ao de outras Costus spp. estudadas por Schemske (1981), sendo autocompatível, mas não apresentando autopolinização espontânea. Ramirez \& Seres (1994) classificaram $C$. spiralis como sendo uma espécie parcialmente autocompatível, por produzir mais sementes por polinização cruzada que por polinização natural. Porém no presente estudo estas diferenças não foram significativas.

O sistema que impede a autopolinização nesta espécie pode ser considerado uma hercogamia de movimento, na qual o estigma é forçado pelo movimento do polinizador quando está forrageando (Webb \& Lloyd 1986). A arquitetura floral de Costus spiralis com o lábio direcionando corretamente o bico do beija-flor no interior da corola (Temeles \& Rankin 2000), permite que este deposite pólen de outras flores no estigma, mas impede que o pólen da mesma flor entre em contato com a superfície receptiva. No entanto, apesar de C. spiralis possuir um mecanismo para evitar a autopolinização, não impede que ocorra a geitonogamia.

A estratégia de apresentar poucas flores por dia aliada ao comportamento de forrageamento dos Phaethornithinae pode favorecer o cruzamento entre indivíduos de diferentes agrupamentos (Siqueira Filho \& Machado 2001). É possível que no início e no final da floração ocorram maiores taxas de polinização cruzada e menores taxas de geitonogamia já que poucas flores estão sendo produzidas diariamente por indivíduo, fazendo com que os beija-flores se desloquem mais entre manchas (Carpenter 1976). 
Em Costus spiralis o número de sementes formadas por polinização natural foi significantemente maior que o número formado por polinizações manuais, resultados semelhantes aos descritos para Costus laevis Ruiz \& Pav., C. allenii Maas e C. guanaiensis Rusby (Schemske 1983). É possível que tais diferenças sejam devidas aos procedimentos de polinização natural que por mais cuidadosos que sejam sempre implicam em dano ou até mesmo contaminação às flores. Mas também o peso e a germinabilidade das sementes resultantes de polinização natural foram maiores, sugerindo que existem outros fatores associados a estas diferenças.

A germinação das sementes provenientes das polinizações manuais não diferiu significativamente entre tratamentos (autopolinização e polinização cruzada). Porém as sementes de polinização natural apresentaram maiores taxas de germinação com $(P<0,001)$ (tabela 2). Schemske (1983) também encontrou maiores taxas de germinação em sementes de polinização natural em 3 espécies do gênero Costus sendo que em duas destas espécies as menores taxas de germinação ocorreram em sementes oriundas de autopolinização. Esses resultados obtidos sugerem que a carga de pólen que cada flor recebe na polinização natural provavelmente é superior em termos de quantidade e variabilidade genética que aquela fornecida pelas polinizações manuais. Estas diferenças devem ser conseqüência do número de visitas, distância de vôo e estratégia de forrageamento dos beija-flores, principalmente Phaethornis pretrei que forrageia em linhas de captura, visitando flores de diferentes agrupamentos em rotas definidas. Este comportamento provavelmente promove o transporte de pólen a distâncias maiores do que aquelas utilizadas neste estudo para as polinizações manuais (> $30 \mathrm{~m})$.

Avaliando o efeito do tipo de polinização apenas na germinação pode-se inferir que em $C$. spiralis não ocorre depressão endogâmica. Tão pouco foram encontradas diferenças significativas, na germinação e nos primeiros meses de crescimento das plântulas de outras espécies de Costus (Schemske 1983). Porém após 12 meses de desenvolvimento ocorreu acentuada diminuição na taxa de crescimento das plântulas oriundas de autopolinzação. Os dados daquele estudo sugerem que a germinação das sementes e os primeiros estágios de estabelecimento de Costus não são afetados pelo tipo de polinização, mas nos estágios posteriores a autopolinização pode implicar em diminuição do "fitness" da progênie.
Os resultados do presente estudo comprovam a maior qualidade nas sementes provenientes de polinização natural. A incapacidade de $C$. spiralis em formar frutos por autopolinização espontânea demonstra que os beija-flores são importantes vetores de pólen, podendo garantir para esta espécie uma elevada taxa de produção de sementes com maior variabilidade genética.

Agradecimentos - Às Dras. Silvana Buzato e Ana Angélica A. Barbosa pelas sugestões na elaboração do manuscrito, ao Ms. Clesnan Mendes-Rodrigues e Dra. Marli A. Ranal pelo auxílio no experimento de germinação e nas análises estatísticas, e à Capes pela bolsa para a primeira autora. $\mathrm{O}$ estudo foi realizado no âmbito do Projeto $\mathrm{CNPq}$ 301778/2004-3.

\section{Referências bibliográficas}

APG II (Angiosperm Phylogeny Group). 2003. An update of the Angiosperm Phylogeny Group classification for the orders and families of flowering plants: APG II. Botanical Journal of The Linnean Society 141:399-436.

ALBUQUERQUE, J.M. 1989. Plantas medicinais de uso popular. Associação Brasileira de Educação Agrícola Superior (ABEAS). Ministério daAgricultura - Secretaria Geral. Brasília.

ANTUNES, A.S., SILVA, B.P. \& PARENTE, J.P. 2000. Flavonol glycosides from leaves of Costus spiralis. Fitoterapia 71:507-510.

AYRES, M., AYRES JÚNIOR, M., AYRES, D.L. \& SANTOS, A.S. 2000. Bioestat 2.0. Mamirauá/MCTCNPq. Belém.

BUZATO, S., SAZIMA, M. \& SAZIMA, I. 2000. Hummingbird-pollinated floras at three atlantic forest sites. Biotropica 32:824-841.

CARPENTER, F.L. 1976. Plant-Pollinator Interactions in Hawaii: Pollination Energetics of Metrosideros collina (Myrtaceae). Ecology 57:1125-1144.

CASTRO, R.D. \& HILHORST, H.W.M. 2004. Embebição e reativação do metabolismo. In Germinação do básico ao aplicado (A.J. Ferreira \& F. Borghetti, orgs.). Editora Artmed, Porto Alegre, p.149-162.

CRONQUIST, A. 1981. An integrated system of classification of flowering plants. Columbia University Press, New York.

DAFNI, A. 1992. Pollination ecology - A practical approach. Oxford University Press. New York.

DAHLGREN, R.M.T., CLIFFORD, H.T. \& YEO, P.F. 1985. The families of the monocotyledons. Springer-Verlag, Berlin.

FEINSINGER, P. \& COWELL, R.K. 1978. Community organization among Neotropical nectar-feeding birds. American Zoologist 18:779-795. 
FIDALGO, O. \& BONONI, V.L.R. 1984. Técnicas de coleta, preservação e herbarização de material botânico. Instituto de Botânica/ Secretaria do Meio Ambiente. São Paulo.

FREITAS, L. \& SAZIMA, M. 2001. Nectar features in Esterhazya macrodonta, a hummingbird-pollinated Scrophulariaceae in Southeastern Brazil. Journal of Plant Research 114:187-191.

GILL, F.B. 1988. Trapline foraging by hermit hummingbirds: Competition for an undefended, renewable resource. Ecology 69:1933-1942.

GRANTSAU, R. 1989. Os beija-flores do Brasil. Editora Expressão e Cultura, Rio de Janeiro.

KAY, K.M. \& SCHEMSKE, D.W. 2003. Pollinator assemblages and visitation rates for 11 especies of Neotropical Costus (Costaceaea). Biotropica 35:198-207.

KEARNS, C.A \& INOUYE, D.W. 1993. Techniques for pollination biologists. Univesity Press of Colorado, Colorado.

KRESS, W.J. 1990. The phylogeny and classification of the Zingiberales. Annals of the Missouri Botanical Garden 77:698-721.

LIMA, S.C., ROSA, R. \& FELTRAN FILHO, A. 1989. Mapeamento do uso do solo no município de Uberlândia - MG, através de imagens TM/LANDSAT. Sociedade \& Natureza 1:127-145.

MAAS, P.J.M. 1972. Costoidae (Zingiberaceae). Flora Neotropica, Monograph n ${ }^{\circ}$ 8. Hafner, New York.

MARTIN, F.W. 1959. Staining and observing pollen tubes in the style by means of fluorescence. Stain Technology 34:125-128.

MARTINS, E.R., CASTRO, D.M., CASTELLANI, D.C. \& DIAS, J.E. 2003. Plantas Medicinais. Editora UFV, Viçosa.

MEDEIROS, M.F.T., FONSECA, V.S. \& ANDREATA, R.H.P. 2004. Plantas medicinais e seus usos pelos sitiantes da Reserva do Rio das Pedras, Mangaratiba, RJ, Brasil. Acta Botanica Brasilica 18:391-399.

NAKAI, T. 1941. Notulae ad Plantas Asiae Orientalis. Journal of Japanese Botany 17:1-15.

NEWSTROM, L.E., FRANKIE, G.W. \& BAKER, H.G. 1994. A new classification for plant phenology based on flowering patterns in lowland tropical rain forest trees at La Selva, Costa Rica. Biotropica 26:141-159.

RADFORD, A.E., DICKINSON, W.C., MASSEY, J.R. \& BELL, C.R. 1974. Vascular plant systematics. Harper \& Row, New York.

RAMIREZ, N. \& SERES, A. 1994. Plant reproductive biology of herbaceous monocots in a Venezuelan tropical cloud forest. Plant Systematics and Evolution 190:129-142.

ROSA, R., LIMA, S.C. \& ASSUNÇÃO, W.L. 1991. Abordagem preliminar das condições climáticas de Uberlândia (MG). Sociedade e Natureza 3:91-108.
SAKAI, S., KATO, M. \& INOUE, T. 1999. Three pollination guilds and variation in floral characteristics of Bornean Gingers (Zingiberaceae and Costaceae). American Journal of Botany 86:646-658.

SAZIMA, I., BUZATO, S. \& SAZIMA 1995. The saw-billed hermit, Ramphodon naevius, and its flowers in southeastern Brazil. Journal Fur Ornithologie 136:195-206.

SAZIMA, I., BUZATO, S. \& SAZIMA, M. 1996. An assemblage of hummingbird-pollinated flowers in a montane forest in southeastern Brazil. Botanica Acta 109:149-160.

SCHEMSKE, D.W. 1980. The evolutionary significance of extrafloral nectar production by Costus woodsonii (Zingiberaceae): An experimental analysis of ant protection. Journal of Ecology 68:959-967.

SCHEMSKE, D.W. 1981. Floral convergence and pollinator sharing in two bee-pollinated tropical herbs. Ecology 62:946-954.

SCHEMSKE, D.W. 1982. Ecological correlates of a Neotropical mutualism: ant assemblages at Costus extrafloral nectaries. Ecology 63:932-941.

SCHEMSKE, D.W. 1983. Breeding system and habitat effects on fitness components in three neotropical Costus (Zingiberaceae). Evolution 37:523-539.

SERES, A. \& RAMIREZ, N. 1995. Biologia floral y polinización de algunas monocotiledoneas de un bosque nublado Venezolano. Annals of the Missouri Botanical Garden 82:61-81.

SICK, H. 1997. Ornitologia Brasileira. Editora Nova Fronteira, Rio de Janeiro.

SILVA, B.P \& PARENTE J.P. 2004. New steroidal saponins from rhizomes of Costus spiralis. Zeitschrift fur Naturforschung, Section C: Journal of Biosciences 59:81-85.

SIQUEIRA FILHO, J.A. \& MACHADO, I.C.S. 2001. Biologia reprodutiva de Canistrum aurantiacum E. Morrem (Bromeliaceae) em remanescente da Floresta Atlântica, Nordeste do Brasil. Acta Botanica Brasilica 15:427-443.

SPECHT, C.D., KRESS, W.J., STEVENSON, D.W.\& DESALLE, R. 2001. A molecular phylogeny of Costaceae (Zingiberales). Molecular Phylogenetics and Evolution 21:333-345.

STEVENSON, D.W.M. \& STEVENSON, J.W. 2004. Costaceae (Costus Family). In Flowering Plants of The Neotropics. (N. Smith, S.A. Mori, A. Henderson, D.W.M. Stevenson \& S.V. Heald, eds.). Princeton University Press, Princeton, p.429-431.

STILES, F.G. 1981. Geographical aspects of bird-flower coevolution, with particular reference to Central America. Annals of the Missouri Botanical Garden 68:323-351.

TEMELES, E.J. \& RANKIN, A.G. 2000. Effect of the lower lip of Monarda didyma on pollen removal by hummingbirds. Canadian Journal of Botany 78:1164-1168. 
VIEL, T.A., DOMINGOS, D.C., SILVA, A.P.M., LIMALANDMAN, M.T.R., LAPA, A.J. \& SOUCCAR, C. 1999. Evaluation of the antiurolithiatic activity of the extract of Costus spiralis (Jacq.) Roscoe in rats. Journal of Ethnopharmacology 66:193-198.
WEBB, C.J. \& LLOYD, D.G 1986. The avoidance of interference between the presentation of pollen and stigmas in angiosperms - II Herkogamy. New Zealand Journal of Botany 24:163-178. 